OPEN ACCESS

Edited by:

Monica Livia Gheorghiu, Carol Davila University of Medicine and Pharmacy, Romania

Reviewed by:

Corin Badiu,

Carol Davila University of Medicine and

Pharmacy, Romania

Nils Lambrecht,

VA Long Beach Healthcare System, United States

*Correspondence:

Ewelina Szczepanek-Parulska ewelina@ump.edu.pl

Specialty section:

This article was submitted to Pituitary Endocrinology,

a section of the journal

Frontiers in Endocrinology

Received: 01 October 2021 Accepted: 29 December 2021 Published: 08 February 2022

Citation:

Krygier A, Szczepanek-Parulska E, Cieślewicz M, Wrotkowska E, Chanaj-Kaczmarek J and Ruchała M

(2022) Iron Homeostasis and

Hepcidin Concentration in

Patients With Acromegaly.

Front. Endocrinol. 12:788247. doi: 10.3389/fendo.2021.788247

\section{Iron Homeostasis and Hepcidin Concentration in Patients With Acromegaly}

\author{
Aleksandra Krygier ${ }^{1}$, Ewelina Szczepanek-Parulska ${ }^{1 *}$, Maja Cieślewicz ${ }^{1}$, \\ Elżbieta Wrotkowska ${ }^{1}$, Justyna Chanaj-Kaczmarek ${ }^{2}$ and Marek Ruchała ${ }^{1}$ \\ ${ }^{1}$ Department of Endocrinology, Metabolism and Internal Medicine, Poznan University of Medical Sciences, Poznan, Poland, \\ 2 Department of Pharmacognosy, Poznan University of Medical Sciences, Poznan, Poland
}

Hepcidin is a protein responsible for maintaining iron $(\mathrm{Fe})$ homeostasis. Data regarding the role of hepcidin in the pathomechanism of Fe balance disturbances associated with acromegaly (AG) are scarce. The aim of the study was to assess the impact of alterations in complete blood count parameters, Fe homeostasis, gonadal status and GH/IGF-1 on the level of hepcidin in AG patients. The study evaluated the differences in hepcidin concentration and iron homeostasis between patients newly diagnosed with $A G$ in comparison to healthy control subjects (CS). We prospectively enrolled 25 adult patients newly diagnosed with AG and 25 healthy volunteers who served as CS. The level of hepcidin was measured using the Hepcidin 25 (bioactive) hs ELISA, which is a highly sensitive enzyme immunoassay for the quantitative in vitro diagnostic measurement (DRG Instruments $\mathrm{GmbH}$, Germany). The median of hepcidin concentration in the serum of patients with AG was significantly lower $9.8(6.2-18.2) \mathrm{ng} / \mathrm{ml}$ as compared to CS 21.3 (14.3-34.0) $\mathrm{ng} / \mathrm{ml}(\mathrm{p}=0.003)$. In the $A G$ group, a statistically significant negative correlation between hepcidin and IGF-1 (rho $=-0.441$ ) was observed. Our study demonstrated a decreased hepcidin level in AG patients in comparison to CS what may have a potentially protective effect against anemia through an increased bioavailability of Fe. Additionally, GH may have a positive direct or indirect effect on erythropoiesis. Further studies on larger patient groups are necessary in order to clarify the exact role of hepcidin in the regulation of erythropoiesis in the excess of GH/IGF-1.

Keywords: hepcidin, iron, erythropoiesis, acromegaly, complete blood count

\section{INTRODUCTION}

Hepcidin constitutes an acute phase liver-derived protein, responsible for maintaining iron $(\mathrm{Fe})$ homeostasis through both local and systemic impact $(1,2)$. Hepcidin triggers the internalization and degradation of ferroportin (the major Fe transporter) which results in a decrease in serum Fe level (3). Therefore, hepcidin level reflects the erythropoietic status of the organism, as erythrocyte production is dependent on the bioavailability of Fe. Iron, in turn, is a crucial ion for heme synthesis, which is a key hemoglobin (HB) component, essential for red blood cells (RBC) production. 
Iron metabolism is controlled by hepcidin on three levels: absorption in the duodenum, release from macrophages, and from hepatocytes (2). Furthermore, hepcidin is regulated by serum Fe level and hepatic Fe stores, representing a homeostatic feedback loop (4-6). There are also other stimulating factors, such as inflammation, autoimmune diseases, chronic kidney diseases $(4,7)$. Conversely, hemolysis, hemorrhage, anemia, and erythropoietin inhibit hepcidin, which enables the restoration of $\mathrm{Fe}$ resources and maintains effective erythropoiesis. Alterations in hepcidin level results in severe disturbances-excessive hepcidin causes Fe deficiency anemia, whereas its deficit leads to Fe overload, or hemochromatosis. Although hepcidin was first identified in 2000 (8), it has recently been evaluated in view of the various endocrine disorders associated with an increase in acute-phase proteins or with concomitant disturbances in Fe homeostasis (9-11). As a result of such reports, a growing awareness of the hormonal influence on Fe metabolism and hepcidin levels has emerged.

Acromegaly $(\mathrm{AG})$ is a rare disease caused by excessive production of the growth hormone $(\mathrm{GH})$ and insulin-like growth factor 1 (IGF1) (12). In more than $90 \%$ of cases, the disorder stems from a GH-secreting pituitary adenoma $(13,14)$, and as a consequence, patients present with somatic growth, metabolic dysfunctions $(15,16)$, and a decreased quality of life (17). The stimulatory effect of $\mathrm{GH}$ on the mammalian erythropoiesis in vitro has been widely recognized $(18,19)$. In fact, Hanley et al. confirmed the promoting effect of both GH and IGF-1 on the hematopoietic colony forming cells in human fetal bone marrow (20). In another study, a decrease in the amount of the hematopoietic bone marrow cells caused by aging observed in rodents was found to be reversed by $\mathrm{GH}$ administration, through an increase in the myeloid colony forming units (21). Moreover, Tsarfaty et al. demonstrated in vivo the stimulation of the hematopoietic progenitor cells in bone marrow following the administration of human recombinant IGF-1, and also its promoting impact on erythroid precursor cells (22). Moreover, the stimulation of erythroid cells by GH and IGF-1 has been demonstrated not only in the bone marrow but also in the peripheral blood (19). Two other previous studies revealed GH involvement in erythropoiesis, showing a significant improvement in erythropoiesis indices which occurred in the course of GH therapy in children suffering from GH deficiency $(23,24)$, although the abovementioned tendency was also observed in adults (25). In fact, insulin-like growth factor 1 is believed to be a key growth-promoting mediator of $\mathrm{GH}$ on human erythroid precursors $(26,27)$. Despite the recognized involvement of $\mathrm{GH}$ in the stimulation of erythropoiesis and altered blood count parameters in AG patients, data regarding the role of hepcidin in the pathomechanism of Fe homeostasis disturbances associated with AG are still scarce.

The objective of the study was to assess the impact of alterations in complete blood count parameters, Fe homeostasis, gonadal status and GH/IGF-1 on the level of hepcidin in AG patients. To the best of our knowledge, this has been the first study evaluating the difference in hepcidin concentration between the newly diagnosed AG patients and the healthy control subjects (CS).

\section{MATERIALS AND METHODS}

The study was prospective and observational. We enrolled 25 adult patients with newly diagnosed AG. The CS comprised 25 healthy volunteers, matched both for age and gender. The diagnosis of $A G$ was based on the following factors: characteristic clinical signs and symptoms, laboratory tests (IGF-1 level above the reference range for age and gender, and $\mathrm{GH}$ level $>0.4 \mathrm{ng} / \mathrm{ml}$ measured by ultrasensitive assay in $75 \mathrm{~g}$ oral glucose tolerance test) and a confirmed pituitary adenoma in magnetic resonance imaging-MRI (12). The strict exclusion criteria for both groups were as follows: anemia, hemolysis, hemorrhage, neoplastic process, autoimmune or inflammatory diseases, chronic kidney or liver diseases, pregnancy or breastfeeding, hemochromatosis, the use of erythropoietin, exogenous supplementation (iron, vitamin B12, folic acid), or surgical therapy (within the previous 6 months).

All patients agreed to participate in the study and signed a written informed consent. The research was conducted in accordance with the Declaration of Helsinki, and was approved by the Poznan University of Medical Sciences Bioethics Committee (approval number: 176/17).

Extensive laboratory assessment was performed in both groups. The level of hepcidin was measured using the Hepcidin 25 (bioactive) hs ELISA, a highly sensitive enzyme immunoassay for the quantitative in vitro diagnostic measurement (DRG Instruments $\mathrm{GmbH}$, Germany). Complete blood count parameters were evaluated by an automated flow cytometer Sysmex-XN 1000 (Sysmex Europe GmbH, Born-barch, Germany). In order to fully investigate $\mathrm{Fe}$ homeostasis, ferritin level was evaluated in Hitachi Cobas e601 chemiluminescent analyzer (Roche Diagnostics), whereas Hitachi Cobas e501 analyzer (Roche Diagnostics) was used to analyze Fe levels. Thyroid gland status was assessed by measuring thyroidstimulating hormone (TSH), free triiodothyronine and thyroxine (fT3, fT4), anti-thyroid peroxidase antibodies (aTPO), and antithyroglobulin antibodies (aTG) using Hitachi Cobas e601 chemiluminescent analyzer (Roche Diagnostics).

Other potential factors, and also chronic kidney and liver diseases, were excluded on the basis of alanine aminotransferase (ALT), aspartate aminotransferase (AST), and C-reactive protein (CRP) measurements using Hitachi Cobas e501 analyzer (Roche Diagnostics). The estimated glomerular filtration rate (eGFR) was assessed by an online medical calculator (https://www. mdcalc.com/mdrd-gfr-equation) based on the MDRD (Modification of Diet in Renal Disease Study) equation.

In terms of the AG patients, GH, IGF-1, prolactin, testosterone and estradiol, and also thyroid (TSH, fT4, fT3) and adrenal function (ACTH, cortisol) were analyzed by Hitachi Cobas e601 chemiluminescent analyzer (Roche Diagnostics). The IGF-1 norm was applied with respect to age and gender, and was presented as a percentage above of the upper normal range for an individual (\%IGF-1). In turn, GH was assessed in oral glucose tolerance test after the administration of $75 \mathrm{~g}$ of glucose, whereas GH concentration for patients with diabetes was determined as a mean value from 5 separate 
measurements in 30-minute intervals (GH five-points profile). Moreover, the volume of pituitary adenoma was evaluated in MRI. A standardized SAGIT questionnaire was completed in all AG patients prior to treatment (where the SAGIT acronym denotes: Signs and symptoms ( $0-4$ points), Associated comorbidities (0-6 points), GH level (0-4 points), IGF-1 level (0-3 points) and Tumor profile ( $0-5$ points) (28). Additionally, the concomitant secondary thyroid and adrenal insufficiency constituted the exclusion criteria.

Statistical analysis was performed using STATISTICA software (StatSoft, Tulsa, Oklahoma, USA) and MedCalc Software (MedCalc Software Ltd, Ostend, Belgium). In most cases, a Shapiro-Wilk test did not reveal the normal distribution for the analysed data, thus, only non-parametric tests were applied, and therefore all values are expressed as median and 25-75\% interquartile range (IQR). Furthermore, we performed Mann-Whitney U-test in order to compare the AG and CS groups. In terms of hepcidin and the parameters related to erythropoiesis, the effect size ( $\eta 2)$ was evaluated. Spearman's rank correlation coefficient was applied to evaluate hepcidin concentration and all the investigated laboratory parameters. Parameters with different gender-dependent reference values were calculated separately (RBCs, HCT, HB, Fe, and ferritin). The level of statistical significance was established at $\mathrm{p}<0.05$.

\section{RESULTS}

The study comprised 25 adult patients with newly diagnosed AG. The CS included 25 healthy volunteers matched for age and gender. Gender distribution in both groups was as follows: men $(\mathrm{n}=16)$ and women $(\mathrm{n}=9)$. The AG patients were aged between 22 and 80 years ( $49 \pm 17$ years), whereas the CS subjects were aged between 28 and 76 years ( $58 \pm 12$ years). We found a slight difference in age between the two groups $(\mathrm{p}=0.04)$, although a correlation between hepcidin and age was not observed.

\section{Hepcidin}

The median (IQR) of hepcidin concentration in the serum of patients with AG amounted to $9.8(6.2-18.2) \mathrm{ng} / \mathrm{ml}$, and was statistically significantly lower $(\mathrm{p}=0.003)$ in comparison to CS $21.3(14.3-34.0) \mathrm{ng} / \mathrm{ml}$ (Figure 1). The effect size $(\eta 2)$ for this group was equal to 0.180 which in interpretation according to Cohen (1988) indicated a large effect, whereas in the interpretation according to Hattie (2009) represented the zone of desired effects. The median of hepcidin in AG women was 7.6 (3.5-9.7) $\mathrm{ng} / \mathrm{ml}$ in comparison to CS women $21.3(14.3-30.9) \mathrm{ng} /$ $\mathrm{ml}$, which was at the limit of statistical significance $(\mathrm{p}=0.09)$, and $\eta 2$ for this group was equal to 0.165 . In the group of men, the difference in median of hepcidin reached statistical significance [p $=0.03,13.0(7.6-22.6)_{\text {AG }}$ vs. $23.9(14.6-37.8)_{\mathrm{CS}} \mathrm{ng} / \mathrm{ml}, \eta 2=$ $0.155]$. The comparison of hepcidin level in the subgroups divided according to gender was presented in Figure 2.

Spearman's rank correlation was used to evaluate hepcidin and all blood parameters analysed in this study, taking into consideration the division according to gender. In the AG group, the calculated coefficient indicated statistically significant ( $\mathrm{p}<0.05)$ negative correlations between hepcidin and IGF-1 (rho $=-0.441$ ), as well as RBC in men (rho $=-0.597$ ). Furthermore, a positive correlation $(p<0.05)$ was found between hepcidin and ferritin in men (rho =0.700). An equivalent analysis was performed in terms of CS, and a

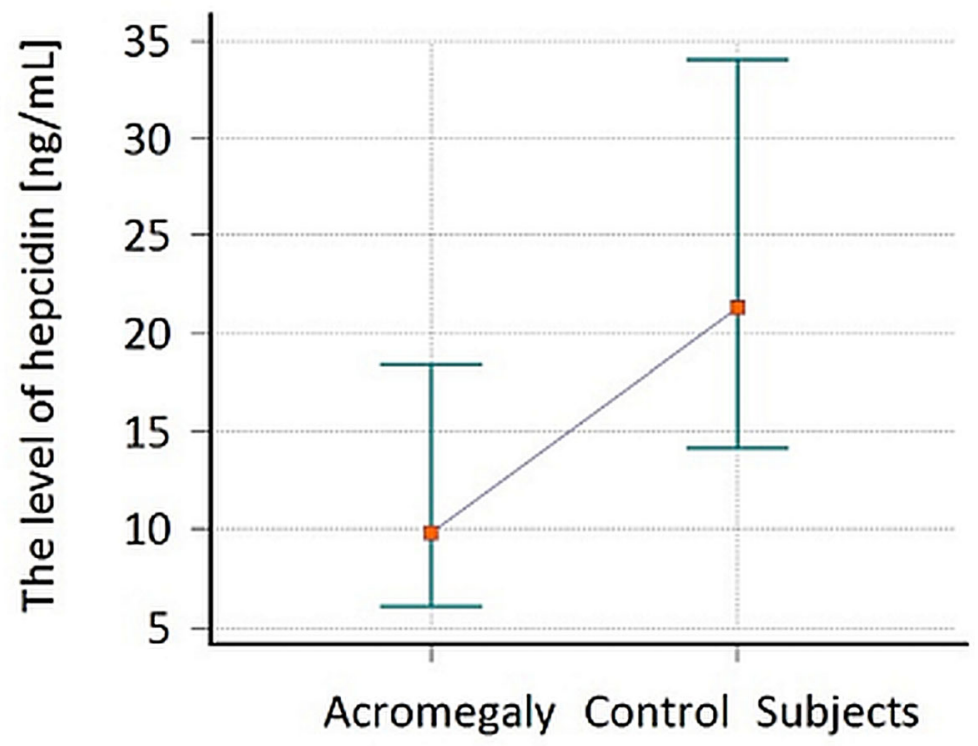

FIGURE 1 | The comparison of hepcidin level in patients with acromegaly (AG) at the time of the diagnosis and in the control subjects (CS). Values are expressed as median and interquartile range (IQR). 

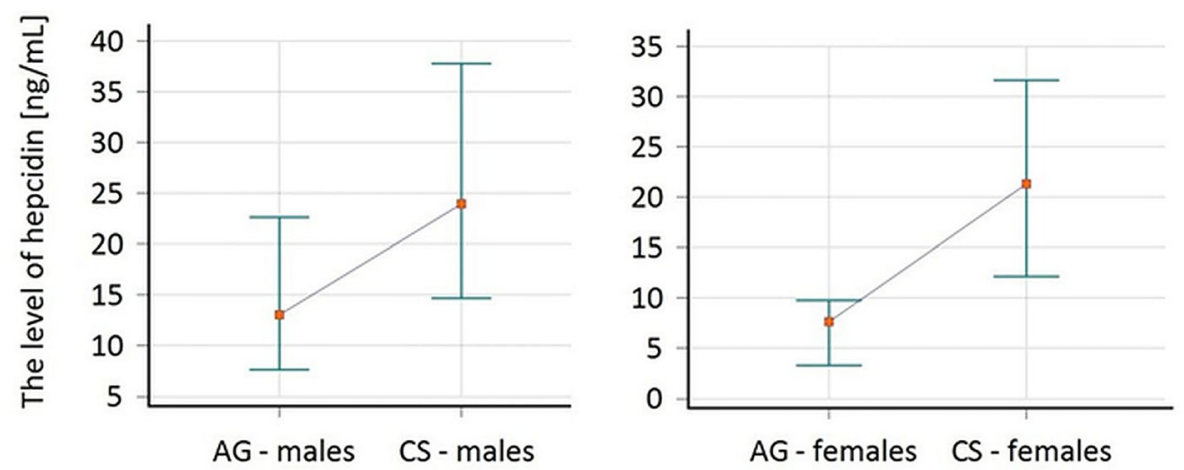

FIGURE 2 | The comparison of hepcidin level in patients with acromegaly (AG) at the time of the diagnosis and in the control subjects (CS) divided by gender. Values are expressed as median and interquartile range (IQR).

statistically significant correlation between hepcidin and ferritin in both genders [male ( $r h o=0.682)$; female $($ rho $=0.867)$ ] was observed.

\section{Other Parameters}

The pituitary function was assessed only in the group of patients with AG. Since the level of IGF-1 depends on age and gender, the percentage over the upper limit of the normal range was calculated. In the group of 16 men, the median of testosterone was $7.1(4.5-9.9) \mathrm{nmol} / \mathrm{L}$, where the normal range with regard to the total testosterone is $9.9-27.8 \mathrm{nmol} / \mathrm{L}$. Twelve of the patients presented with hypogonadism due to pituitary gland adenoma and in the rest (4 of 16 men) we observed a correct activity of the pituitary-gonadal axis. Despite normal gonadotropin secretion, the median levels of testosterone were in the lower reference range. Moreover, 7 out of 9 women were in postmenopausal period and the level of estradiol was below $5 \mathrm{pg} / \mathrm{ml}$. A nonsignificant correlation between the level of hepcidin and testosterone or estradiol was noted [Spearman's rank correlation between hepcidin and testosterone was rho = $-0.594(\mathrm{p}>0.05)$, and for estradiol rho $=-0.365(\mathrm{p}>0.05)]$. Additionally, the median level of prolactin was 278 (IQR 219393) $\mu \mathrm{IU} / \mathrm{ml}$ in women and $379(240-648) \mu \mathrm{IU} / \mathrm{ml}$ in men. One female patient presented a higher value of prolactin; nevertheless, she was in the postmenopausal period, whereas a mild hyperprolactinemia was observed in 7 out of 16 male subjects (Table 1).

\section{Comparisons}

A comparison of both AG and CS groups revealed significant differences (provided in Table 2). The median ferritin in men with AG $94.0(59.0-142.0) \mathrm{ng} / \mathrm{ml}$ was statistically significantly decreased $(\mathrm{p}=0.02)$ as compared to CS $184.0(112.5-245.0) \mathrm{ng} /$ $\mathrm{ml}$. The parameters of thyroid, liver, kidney or inflammation potentially influencing hepcidin level did not present significant differences.

\section{Correlations}

All parameters in both groups involved in the study were correlated; therefore, we presented the most significant

TABLE 1 | The parameters evaluated in acromegaly group.

\begin{tabular}{|c|c|c|c|}
\hline Parameter & Reference range & Acromegaly group AG & Control subjects CS \\
\hline IGF-1 (ng/ml) & norm for age and gender & 775 (675-959) & - \\
\hline$\% \mid G F-1$ & $\%$ of normal range for age and gender & 304 (220-345) & - \\
\hline $\mathrm{GH} /$ test $^{\mathrm{a}}(\mathrm{ng} / \mathrm{ml})$ & $<0.4$ & $7.4(5.1-21.5)$ & - \\
\hline GH/profile ${ }^{\mathrm{b}}$ (ng/ml) & $<2.5$ & $14.6(4.8-17.2)$ & - \\
\hline $\mathrm{V}\left(\mathrm{mm}^{3}\right)$ & - & $2,040(572-4,725)$ & - \\
\hline SAGIT & $0-26$ & $13(11-15)$ & - \\
\hline Testosterone in men (nmol/L) & $9.9-27.8$ & $7.1(4.5-9.9)$ & - \\
\hline \multirow[t]{2}{*}{ Prolactin $(\mu \mathrm{l} \mathrm{U} / \mathrm{ml})$} & $70-510^{c}$ & 278 (219-393) & - \\
\hline & $85-390^{d}$ & $379(240-648)$ & - \\
\hline Hepcidin (ng/ml) & $0.2-47.7$ & $9.8(6.2-18.2)$ & $21.3(14.3-34.0)$ \\
\hline
\end{tabular}

Values are expressed as median (IQR).

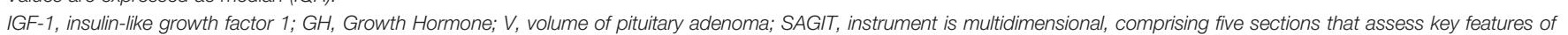
acromegaly: signs and symptoms (S), associated comorbidities (A), GH levels (G), IGF-1 levels (I), and the Tumor profile (T).

a In oral glucose tolerance test.

${ }^{b}$ Five-point profile of growth hormone.

${ }^{c}$ Female.

${ }^{d}$ Male. 
TABLE 2 | Biochemical parameters in patients with AG at the moment of diagnosis compared to CS.

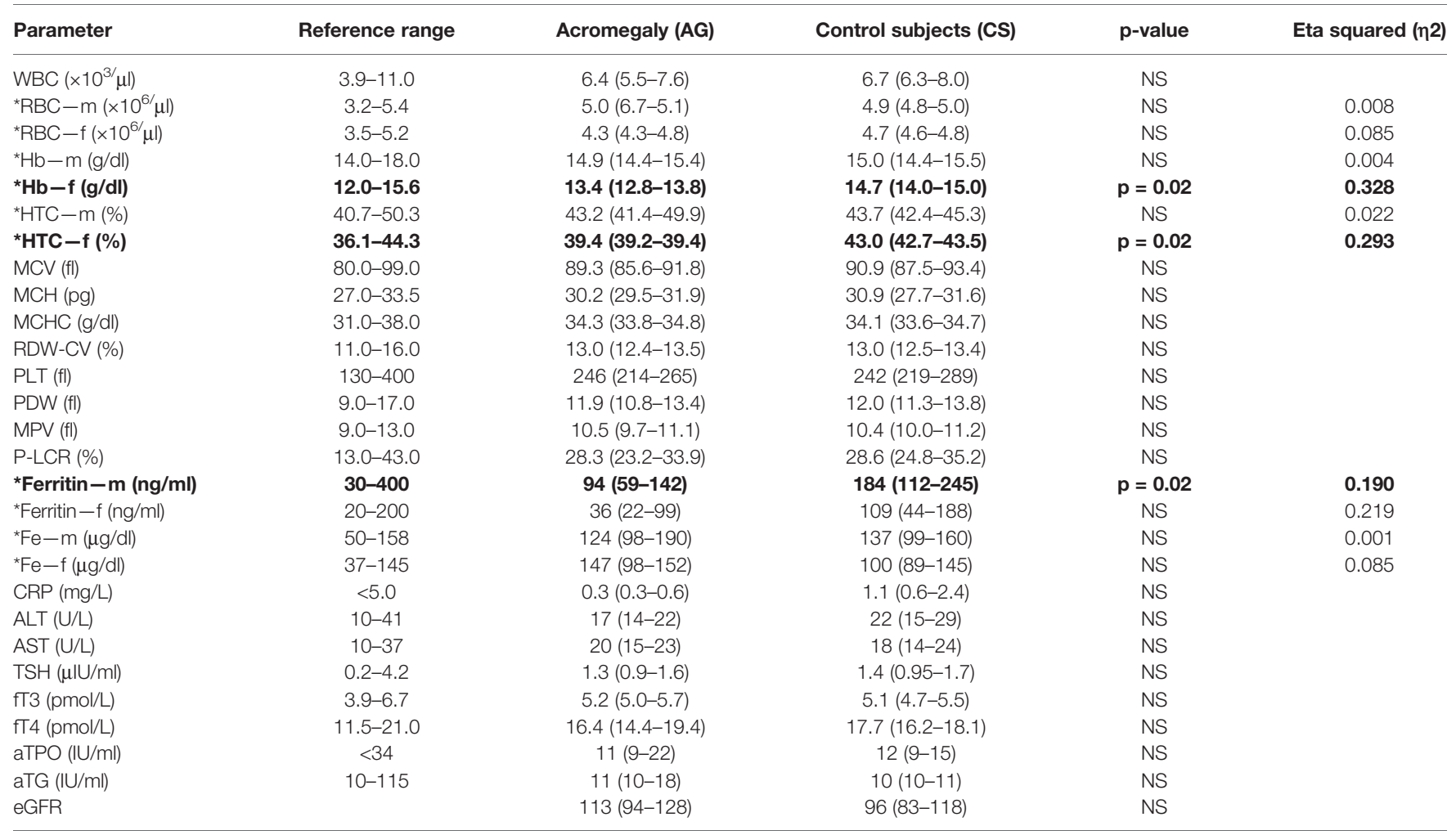

Values are expressed as median (IQR) for non-parametric tests (Mann-Whitney U-test).

NS, non-significant.

*Parameters with different reference range in men and women; $m$, male; $f$, female.

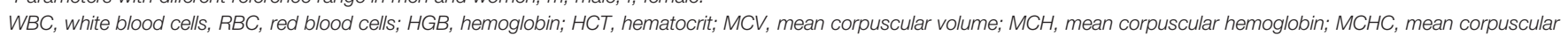

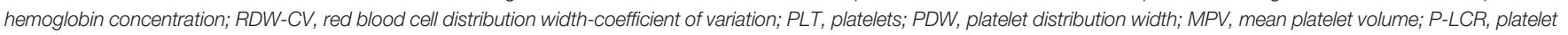

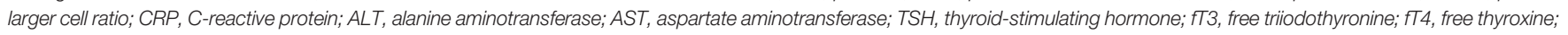
aTPO, anti-thyroid peroxidase antibody; aTG, anti-thyroglobulin antibody; Fe, iron; e-GFR, estimated glomerular filtration rate.

Bold values are statistically significant ( $p$ value $<0.05$ ).

correlations. In both study groups (AG and CS) we observed a positive, statistically significant correlation between the mean corpuscular volume (MCV) and mean corpuscular hemoglobin $(\mathrm{MCH})$ (rho $=0.912_{\mathrm{AG}}$ vs. $0.713_{\mathrm{CS}}$ ), and also $\mathrm{RBC}$ and hematocrit (HTC) (rho in men $0.685_{\mathrm{AG}}$ vs. $0.705_{\mathrm{CS}}$, rho in women $0.748_{\mathrm{AG}}$ vs. $\left.0.667_{\mathrm{CS}}\right)$. In the male group, we demonstrated also a correlation between $\mathrm{RBC}$ and $\mathrm{HB}$ ( $\mathrm{p}<0.05$, rho $=0.686_{\mathrm{AG}}$ vs. $0.580_{\mathrm{CS}}$ ), whereas in the female group, a correlation with $\mathrm{HB}$ and $\mathrm{HTC}\left(\mathrm{p}<0.05\right.$, rho $=0.752_{\mathrm{AG}}$ vs. $0.850_{\mathrm{CS}}$ ) was found.

In the male $A G$ group of patients we demonstrated a statistically significant correlation between RBC and MCV $($ rho $=-0.630), \mathrm{RBC}$ and $\mathrm{MCH}(\mathrm{rho}=-0.662), \mathrm{RBC}$ and ferritin (rho $=-0.668)$, MCV and ferritin (rho $=0.702$ ), $\mathrm{MCH}$ and ferritin (rho $=0.750)$, and also HB and HTC (rho $=0.885)$. In terms of the female subgroup correlations $(\mathrm{p}<0.05)$ between RBC and MCV (rho $=-0.900)$ as well as $\mathrm{RBC}$ and $\mathrm{MCH}$ (rho $=-0.850$ ) were observed. Furthermore, in the AG group, a statistically significant correlation was noted between IGF-1 and SAGIT (rho = $0.426)$, \% IGF- 1 and Fe in men (rho $=0.532)$, as well as \% IGF-1 and TSH (rho $=0.428)$.

\section{DISCUSSION}

To the best of our knowledge, this has been the first study which prospectively evaluated differences in hepcidin concentration between the newly diagnosed AG patients and healthy CS. Moreover, we profoundly assessed the impact of alterations in complete blood count parameters, $\mathrm{Fe}$ homeostasis, gonadal status and GH/IGF-1 on the level of hepcidin in AG patients.

In all patients with newly diagnosed AG, and following the gender subdivision, we observed a decreased level of hepcidin in comparison to the CS. In fact, a median serum hepcidin concentration was decreased more than two times in the AG group than in the CS. A potential explanation of the observed change includes an impact of elevated $\mathrm{GH}$, and consequently IGF-1 (29), which constitute crucial pathogenetic factors in the development of AG, and significantly affect hepcidin concentration levels and $\mathrm{Fe}$ homeostasis. According to the study by Troutt et al. in 2012, a reduction of hepcidin level following GH administration in the healthy volunteers was found, which was presumably due to the stimulating effect on erythropoiesis (30) reported in the previous studies $(18,19,27)$. 
Considering the role of hepcidin, a decrease in this protein in the AG group should potentially cause a greater bioavailability of iron and ferroportin, resulting in an increase in erythropoiesis. However, it was not observed; in fact, the pro-erythropoiesis parameters (ferritin, iron) were either the same or lower in the AG group compared to the CS group. Moreover, we did not observe statistically significant differences in the complete blood count between AG and CS, except HB and HTC in female patients. Both aforementioned parameters were lower in the AG group than in the CS group, nevertheless, they were still within the normal range with the simultaneous normal level of Fe and ferritin.

An example of a special situation, where hepcidin is inhibited or low, while there is no iron overload in the blood, is pregnancy. Van Santen et al. have noted a significant decrease of hepcidin since the second trimester of gestation that persists through the rest of the pregnancy (31). This trend was likely related to the increase of iron consumption by fetus growth, which could be recognized in the corresponding lowering in serum iron and erythropoietic parameters. We hypothesize that in acromegaly there might be a similar situation, and iron is intensively used for tissues and organs overgrowth. According to the current state of knowledge on iron homeostasis regulation, when tissue iron demands are high, hepcidin concentrations are low and vice versa (32-34). Such a situation takes place in patients with acromegaly. If the iron is required, it can be exported rapidly across the enterocyte basolateral membrane via ferroportin 1 . It is then bounded to transferrin which distributes it around the body to the sites of utilization. Tissues with high proliferative capacity require large amounts of iron and express TfR 1 on their plasma membrane. Thus, when iron supply becomes limited, its distribution to tissues becomes prioritized, possibly even at the expense of erythropoiesis. This may at least partially explain why we do not observed high Fe and erythrocyte indices in the blood of patients with AG.

The other possible explanation might be the direct influence of $\mathrm{GH} / \mathrm{IGF}-1$ on other regulators of iron homeostasis, i.e., suppression of divalent metal-iron transporter 1 (DMT1), responsible for nonheme iron import across the apical membrane of the enterocyte. The exact mechanisms of regulation of DMT1 are still not fully understood, however at least three possible mechanisms may be involved (translational regulation through IRE-IRP binding, interaction of PCBP2, degradation by ubiquitination depending on iron level) (35).

All patients participating in the study underwent both gastroand colonoscopy at the time of the AG diagnosis to exclude active neoplasms and their influence on iron homeostasis parameters. According to Ward et al. and Xiang-Tao et al., the expression of hepcidin gene is enhanced in colorectal carcinogenesis, although it does not trigger systemic anemia. Low complete blood count parameters were associated with the increased colon cancer staging (36). Moreover, Xiang-Tao indicated that the expression of hepcidin depended on tumor stage (37). Therefore, it is possible to conclude that early stage lesions, such as polyps, are rather unlikely to interfere with our results.
The influence of GH and IGF-1 on erythropoiesis has already been demonstrated on multiple levels. The process of erythropoiesis depends on the production of RBCs which relies on the bioavailability of $\mathrm{Fe}$-an important component of heme in $\mathrm{HB}$, and also on the erythropoietin stimulating proliferation and differentiation of erythroid progenitor cells (29). GH and IGF-1 stimulate growth of erythroid precursor cells in the presence of erythropoietin. Additionally, GH receptors are present in the bone marrow (18), and IGF-1 receptors are located in erythrocytes. It has been hypothesized that the activity of $\mathrm{GH}$ is mainly mediated by IGF-1, which has a similar activity to erythropoietin and can act both directly, and also through the enhanced production of erythropoietin $(23,38,39)$. In fact, Anttila et al. reported a positive correlation between serum IGF-1 and $\mathrm{HB}$ in healthy children (40). Furthermore, GH insufficiency patients develop anemia with low erythropoietin levels $(20,25)$. In contrast, Petrossians et al. did not observe any correlations between RBC (analysed separately for male and female patients) and GH in AG patients, although they noticed a limited statistical correlation between RBC count and IGF-1. Additionally, they also found no correlation of $\mathrm{HB}$ with $\mathrm{GH}$, but observed a positive correlation with IGF-1 (41).

Fe concentration levels in both study groups in our research were similar. However, in the AG male group the level of ferritin ( $\mathrm{p}<0.05$ ) was twice as low as in the CS group, although still within the reference range. Ferritin, in turn, is a protein responsible for Fe storage and a marker of inflammation (42). According to the previous research, a decrease in ferritin levels has been linked to Fe deficiency (43). Decreased ferritin in AG, indicative of relative depletion in Fe stores, may potentially account for the decreased hepcidin observed in the AG group. In view of the pathophysiological mechanism of acromegaly, reduced blood count parameters (HB, HTC), together with Fe concentration within the normal limits, may suggest the utilization of $\mathrm{Fe}$ in other processes. This is presumably due to the previously mentioned increased $\mathrm{Fe}$ demand during organ overgrowth or the conversion of ribose nucleotides to deoxyribose nucleotides, which is an essential process for DNA replication and cell division (44), enhanced in AG (45).

The previously widely recognized positive correlation between hepcidin and ferritin (9-11), was repeatedly confirmed in our study, and was particularly evident in men. The recognized hepcidin suppressors include sex hormones (testosterone, 17 $\beta$-estradiol, progesterone), and erythropoiesis [through ligands and/or modulators, such as erythroferrone (ERFE), growth differentiation factor 15 (GDF15), twistedgastrulation 1 (TWSG1), and growth factors [hepatocyte growth factor (HGF), epidermal growth factor (EGF), plateletderived growth factor $\mathrm{BB}$ (PDGF-BB)]. Additionally, Goodnough et al. noticed that IGF-1 and IGF-2 had no impact on hepcidin expression in the primary hepatocytes $(46,47)$. The well-defined regulatory pathways of hepcidin include the BMPSMAD pathway (mediating the effect of Fe and inflammation on hepcidin), the IL-6 pathway (mediating the effect of inflammation), and the EPO-ERFE axis (mediating hepcidin suppression by erythropoietic activity) (46). 
The AG patients and CS were euthyroid, with no autoimmune thyroid diseases and did not present with overt anemia, chronic liver or kidney disease and inflammation. The majority of male patients with acromegaly (75\%) developed partial hypogonadotropic hypogonadism, whereas $78 \%$ women were in postmenopausal period, and/or suffered from the secondary gonadal failure. In the men from the CS group, the level of testosterone was not measured; however, it can be assumed that the studied groups were representative of each other, since the testosterone level in men tends to decrease with age, as confirmed by Feldman et al. (48). Most of the healthy women were in the postmenopausal age.

Previous clinical and experimental observations suggested that elevated levels of estrogen and testosterone may downregulate hepcidin synthesis (44). In 2012, Hou et al. investigated the biological effect of estrogen on Fe metabolism in the mouse model. Mice following ovariectomy presented a decreased $\mathrm{HB}$ and Fe serum concentrations, although tissue $\mathrm{Fe}$ level in the liver and spleen was increased. The transcription of hepatic hepcidin was elevated in the ovariectomized mice compared to the control mice, which confirmed that estrogen greatly contributes to $\mathrm{Fe}$ homeostasis by regulating hepatic hepcidin expression directly through a functional estrogen response element in the promoter region of hepcidin gene (49). Subsequently, Yang et al. observed an inhibition of hepcidin synthesis induced by $17 \beta$-estradiol, and an increased $\mathrm{Fe}$ uptake, a mechanism to compensate Fe loss during menstruation (50). Recent studies have confirmed that estrogen activity contributes to the changes in serum $\mathrm{Fe}$ status; a negative correlation between hepcidin and estrogen or Fe was demonstrated in menstruating women which is a mechanism increasing serum Fe content (51). The latest reports indicated that testosterone suppressed hepcidin (44), either through direct or indirect mechanisms, resulting in the increased $\mathrm{Fe}$ turnover and maintaining erythropoiesis during severe energy deficit (52). Furthermore, Guo et al. emphasized the negative impact of testosterone on hepcidin, which increases Fe availability and erythropoiesis. However, it was also demonstrated that hepcidin suppression was not essential for mediating effects of testosterone on erythropoiesis in healthy mice (53).

Therefore, in our study, we excluded the reducing effect of estrogen and testosterone on hepcidin levels in the AG group. As in the AG group, a decreased hepcidin level was noted, regardless of the gonadal function compared to the CS. We also observed a statistically significant negative correlation of hepcidin and IGF1 , as well as positive correlation of \%IGF-1 and Fe in the male group. Thus, we may suggest that in patients with AG, the crucial influence on low hepcidin levels was the concentration of $\mathrm{GH}$ / IGF-1 and/or Fe homeostasis.

Another issue worth noting is the prolactin concentration in our group. In the literature the data with regard to the influence of prolactin levels on hepcidin concentration is scarce. We have found only one report on 40 serum samples from non-pregnant hyperprolactinemic women, where the authors noticed a decreased level of hepcidin in comparison to controls with normal prolactin concentration. This may constitute a limitation in our study, since we cannot exclude the effect of elevated prolactin levels on hepcidin (54). However, in our group only one woman and few men presented with only mild hyperprolactinemia. Patients with high prolactin levels (above 3 times the upper limit of the normal value) with a high probability of a mixed GH-prolactin secreting tumor, were not included in the analysis. Moreover, Wang et al. provided evidence that prolactin directly supresses hepcidin expression (54). Taking into account that prolactin and growth hormone are largely analogues in their chemical structure and active center (prolactin-peptide hormone with 199 amino acids, growth hormone-peptide hormone with 191 amino acids), function and origin from the anterior pituitary lobe $(55,56)$, we may assume that growth hormone may exert similar physiological effect on hepcidin.

In conclusion, our study demonstrates a decreased hepcidin level in AG patients in comparison to the CS group, which may have a potentially protective effect against anemia through an increase in the bioactivity of Fe. Additionally, GH may positively affect erythropoiesis, both directly and indirectly. Further studies on larger groups of patients are required to investigate the exact role of hepcidin in the regulation of erythropoiesis in the excess of $\mathrm{GH} / \mathrm{IGF}-1$.

\section{DATA AVAILABILITY STATEMENT}

The raw data supporting the conclusions of this article will be made available by the authors, without undue reservation.

\section{ETHICS STATEMENT}

The studies involving human participants were reviewed and approved by the Bioethical Committee of Poznan University of Medical Sciences. The patients/participants provided their written informed consent to participate in this study.

\section{AUTHOR CONTRIBUTIONS}

AK, ES-P, and MR performed the study design. AK and ES-P performed data acquisition and interpretation. AK performed statistical analysis. EW and JC-K were involved in the laboratory measurements. AK, ES-P, and MC prepared the manuscript. ES-P and MR completed the final revision of the manuscript. All authors contributed to the article and approved the submitted version.

\section{FUNDING}

The work was supported by the PRELUDIUM 12 grant from the Polish National Centre for Science (2016/23/N/NZ5/02573). 


\section{REFERENCES}

1. Pigeon C, Ilyin G, Courselaud B, Leroyer P, Turlin B, Brissot P, et al. A New Mouse Liver-Specific Gene, Encoding a Protein Homologous to Human Antimicrobial Peptide Hepcidin, is Overexpressed During Iron Overload. J Biol Chem (2001) 276:7811-9. doi: 10.1074/jbc.M008923200

2. Ganz T, Nemeth E. Hepcidin and Disorders of Iron Metabolism. Annu Rev Med (2011) 62:347-60. doi: 10.1146/annurev-med-050109-142444

3. Donovan A, Lima CA, Pinkus JL, Pinkus GS, Zon LI, Robine S, et al. The Iron Exporter Ferroportin/Slc40al is Essential for Iron Homeostasis. Cell Metab (2005) 1:191-200. doi: 10.1016/j.cmet.2005.01.003

4. Ganz T, Olbina G, Girelli D, Nemeth E, Westerman M. Immunoassay for Human Serum Hepcidin. Blood (2008) 112:4292-7. doi: 10.1182/blood-200802-139915

5. Corradini E, Meynard D, Wu Q, Chen S, Ventura P, Pietrangelo A, et al. Serum and Liver Iron Differently Regulate the Bone Morphogenetic Protein 6 (BMP6)-SMAD Signaling Pathway in Mice. Hepatology (2011) 54:273-84. doi: 10.1002/hep.24359

6. Ramos E, Kautz L, Rodriguez R, Hansen M, Gabayan V, Ginzburg Y, et al. Evidence for Distinct Pathways of Hepcidin Regulation by Acute and Chronic Iron Loading in Mice. Hepatology (2011) 53:1333-41. doi: 10.1002/hep.24178

7. Ruchala P, Nemeth E. The Pathophysiology and Pharmacology of Hepcidin. Trends Pharmacol Sci (2014) 35:155-61. doi: 10.1016/j.tips.2014.01.004

8. Simetic L, Zibar L. Laboratory Use of Hepcidin in Renal Transplant Recipients. Biochem Med (Zagreb) (2016) 26:34-52. doi: 10.11613/BM.2016.003

9. Hernik A, Szczepanek-Parulska E, Filipowicz D, Abdolall A, Borowczyk M, Wrotkowska E, et al. The Hepcidin Concentration Decreases in Hypothyroid Patients With Hashimoto's Thyroiditis Following Restoration of Euthyroidism. Sci Rep (2019) 9:16222. doi: 10.1038/s41598-019-52715-3

10. Hernik A, Szczepanek-Parulska E, Filipowicz D, Czarnywojtek A, Wrotkowska E, Kramer L, et al. Hepcidin and Iron Homeostasis in Patients With Subacute Thyroiditis and Healthy Subjects. Mediators Inflamm (2019) 2019:5764061. doi: 10.1155/2019/5764061

11. Krygier A, Szczepanek-Parulska E, Filipowicz D, Ruchala M. Changes in Serum Hepcidin According to Thyrometabolic Status in Patients With Graves' Disease. Endocr Connect (2020) 9(3):234-42. doi: 10.1530/EC-20-0017

12. Bolanowski M, Ruchala M, Zgliczynski W, Kos-Kudla B, HubalewskaDydejczyk A, Lewinski A. Diagnostics and Treatment of Acromegaly Updated Recommendations of the Polish Society of Endocrinology. Endokrynol Pol (2019) 70:2-18. doi: 10.5603/EP.a2018.0093

13. Marinescu MC, Baciu I, Baculescu N, Capatina CA, Dusceac R, Galoiu S, et al. Improvement of Acromegaly Control With Multimodal Therapy in Romania. Endokrynol Pol (2020) 71:235-9. doi: 10.5603/EP.a2020.0020

14. Kaluzny M, Polowczyk B, Bladowska J, Kubicka E, Bidlingmaier M, Bolanowski M, et al. Acromegaly Due to Ectopic Growth HormoneReleasing Hormone Secretion by Lung Carcinoid. Pol Arch Intern Med (2020) 130:685-7. doi: 10.20452/pamw.15337

15. Popielarz-Grygalewicz A, Stelmachowska-Banas M, Gasior JS, Grygalewicz P, Czubalska M, Zgliczynski W, et al. Subclinical Left Ventricular Systolic Dysfunction in Patients With Naive Acromegaly - Assessment With TwoDimensional Speckle-Tracking Echocardiography: Retrospective Study. Endokrynol Pol (2020) 71:227-34. doi: 10.5603/EP.a2020.0021

16. Ruchala M, Szczepanek-Parulska E, Fularz M, Wolinski K. Risk of Neoplasms in Acromegaly. Contemp Oncol (Pozn) (2012) 16:111-7. doi: 10.5114/ wo.2012.28790

17. Bolanowski M, Hubalewska-Dydejczyk A, Kos-Kudla B, Ruchala M, Witek P, Zgliczynski W, et al. Quality of Life in Patients With Acromegaly Receiving Lanreotide Autogel: A Real-World Observational Study. Endokrynol Pol (2021) 72(5):512-9. doi: 10.5603/EP.a2021.0075

18. Golde DW, Bersch N, Li CH. Growth Hormone: Species-Specific Stimulation of Erythropoiesis In Vitro. Science (1977) 196:1112-3. doi: 10.1126/ science.870971

19. Claustres M, Chatelain P, Sultan C. Insulin-Like Growth Factor I Stimulates Human Erythroid Colony Formation In Vitro. J Clin Endocrinol Metab (1987) 65:78-82. doi: 10.1210/jcem-65-1-78

20. Hanley MB, Napolitano LA, McCune JM. Growth Hormone-Induced Stimulation of Multilineage Human Hematopoiesis. Stem Cells (2005) 23:1170-9. doi: 10.1634/stemcells.2004-0322
21. French RA, Broussard SR, Meier WA, Minshall C, Arkins S, Zachary JF, et al. Age-Associated Loss of Bone Marrow Hematopoietic Cells is Reversed by GH and Accompanies Thymic Reconstitution. Endocrinology (2002) 143:690-9. doi: 10.1210/endo.143.2.8612

22. Tsarfaty G, Longo DL, Murphy WJ. Human Insulin-Like Growth Factor I Exerts Hematopoietic Growth-Promoting Effects After In Vivo Administration. Exp Hematol (1994) 22:1273-7.

23. Ciresi A, Piazza G, Radellini S, Guarnotta V, Mineo MG, Giordano C. Growth Hormone and Hematopoiesis: A Retrospective Analysis on a Large Cohort of Children With Growth Hormone Deficiency. Growth Horm IGF Res (2018) 42-43:8-13. doi: 10.1016/j.ghir.2018.07.005

24. Kawa MP, Stecewicz I, Piecyk K, Pius-Sadowska E, Paczkowska E, Roginska D, et al. Effects of Growth Hormone Therapeutic Supplementation on Hematopoietic Stem/Progenitor Cells in Children With Growth Hormone Deficiency: Focus on Proliferation and Differentiation Capabilities. Endocrine (2015) 50:162-75. doi: 10.1007/s12020-015-0591-0

25. Christ ER, Cummings MH, Westwood NB, Sawyer BM, Pearson TC, Sonksen $\mathrm{PH}$, et al. The Importance of Growth Hormone in the Regulation of Erythropoiesis, Red Cell Mass, and Plasma Volume in Adults With Growth Hormone Deficiency. J Clin Endocrinol Metab (1997) 82:2985-90. doi: 10.1210/jc.82.9.2985

26. Ronnestad A, Moe PJ, Breivik N. Enhancement of Erythropoiesis by Erythropoietin, Bovine Protein and Energy Fortified Mother's Milk During Anaemia of Prematurity. Acta Paediatr (1995) 84:809-11. doi: 10.1111/j.16512227.1995.tb13762.x

27. Kurtz A, Zapf J, Eckardt KU, Clemons G, Froesch ER, Bauer C. InsulinLike Growth Factor I Stimulates Erythropoiesis in Hypophysectomized Rats. Proc Natl Acad Sci USA (1988) 85:7825-9. doi: 10.1073/pnas.85. 20.7825

28. Giustina A, Bronstein MD, Chanson P, Petersenn S, Casanueva FF, Sert C, et al. Staging and Managing Patients With Acromegaly in Clinical Practice: Baseline Data From the SAGIT(R) Validation Study. Pituitary (2019) 22:47687. doi: 10.1007/s11102-019-00977-5

29. Rosenfeld RG, Hwa V. The Growth Hormone Cascade and its Role in Mammalian Growth. Horm Res (2009) 71(Suppl 2):36-40. doi: 10.1159/ 000192434

30. Troutt JS, Rudling M, Persson L, Stahle L, Angelin B, Butterfield AM, et al. Circulating Human Hepcidin-25 Concentrations Display a Diurnal Rhythm, Increase With Prolonged Fasting, and are Reduced by Growth Hormone Administration. Clin Chem (2012) 58:1225-32. doi: 10.1373/clinchem. 2012.186866

31. van Santen S, Kroot JJ, Zijderveld G, Wiegerinck ET, Spaanderman ME, Swinkels DW. The Iron Regulatory Hormone Hepcidin is Decreased in Pregnancy: A Prospective Longitudinal Study. Clin Chem Lab Med (2013) 51:1395-401. doi: 10.1515/cclm-2012-0576

32. Anderson GJ, Frazer DM. Current Understanding of Iron Homeostasis. Am J Clin Nutr (2017) 106:1559S-66S. doi: 10.3945/ajen.117.155804

33. Vogt AS, Arsiwala T, Mohsen M, Vogel M, Manolova V, Bachmann MF. On Iron Metabolism and Its Regulation. Int J Mol Sci (2021) 22(9):4591. doi: 10.3390/ijms22094591

34. Gao G, Li J, Zhang Y, Chang YZ. Cellular Iron Metabolism and Regulation. Adv Exp Med Biol (2019) 1173:21-32. doi: 10.1007/978-981-13-9589-5_2

35. Yanatori I, Kishi F. DMT1 and Iron Transport. Free Radic Biol Med (2019) 133:55-63. doi: 10.1016/j.freeradbiomed.2018.07.020

36. Ward DG, Roberts K, Brookes MJ, Joy H, Martin A, Ismail T, et al. Increased Hepcidin Expression in Colorectal Carcinogenesis. World J Gastroenterol (2008) 14:1339-45. doi: 10.3748/wjg.14.1339

37. Xiang-Tao P. Expression of Hepcidin and Neogenin in Colorectal Cancer. Open Med (Wars) (2017) 12:184-8. doi: 10.1515/med-2017-0027

38. Polychronakos C, Guyda HJ, Posner BI. Receptors for the Insulin-Like Growth Factors on Human Erythrocytes. J Clin Endocrinol Metab (1983) 57:436-8. doi: 10.1210/jcem-57-2-436

39. Correa PN, Axelrad AA. Production of Erythropoietic Bursts by Progenitor Cells From Adult Human Peripheral Blood in an Improved Serum-Free Medium: Role of Insulinlike Growth Factor 1. Blood (1991) 78:2823-33. doi: 10.1182/blood.V78.11.2823.bloodjournal78112823

40. Anttila R, Koistinen R, Seppala M, Koistinen H, Siimes MA. Insulin-Like Growth Factor I and Insulin-Like Growth Factor Binding Protein 3 as 
Determinants of Blood Hemoglobin Concentration in Healthy Subjects. Pediatr Res (1994) 36:745-8. doi: 10.1203/00006450-199412000-00011

41. Petrossians P, Daly AF, Natchev E, Maione L, Blijdorp K, Sahnoun-Fathallah $\mathrm{M}$, et al. Acromegaly at Diagnosis in 3173 Patients From the Liege Acromegaly Survey (LAS) Database. Endocr Relat Cancer (2017) 24:505-18. doi: 10.1530/ ERC-17-0253

42. Knovich MA, Storey JA, Coffman LG, Torti SV, Torti FM. Ferritin for the Clinician. Blood Rev (2009) 23:95-104. doi: 10.1016/j.blre.2008.08.001

43. Wang W, Knovich MA, Coffman LG, Torti FM, Torti SV. Serum Ferritin: Past, Present and Future. Biochim Biophys Acta (2010) 1800:760-9. doi: 10.1016/j.bbagen.2010.03.011

44. Roth MP, Meynard D, Coppin H. Regulators of Hepcidin Expression. Vitam Horm (2019) 110:101-29. doi: 10.1016/bs.vh.2019.01.005

45. Shea BT, Hammer RE, Brinster RL. Growth Allometry of the Organs in Giant Transgenic Mice. Endocrinology (1987) 121:1924-30. doi: 10.1210/endo-1216-1924

46. Sangkhae V, Nemeth E. Regulation of the Iron Homeostatic Hormone Hepcidin. Adv Nutr (2017) 8:126-36. doi: 10.3945/an.116.013961

47. Goodnough JB, Ramos E, Nemeth E, Ganz T. Inhibition of Hepcidin Transcription by Growth Factors. Hepatology (2012) 56:291-9. doi: 10.1002/hep. 25615

48. Feldman HA, Longcope C, Derby CA, Johannes CB, Araujo AB, Coviello AD, et al. Age Trends in the Level of Serum Testosterone and Other Hormones in Middle-Aged Men: Longitudinal Results From the Massachusetts Male Aging Study. J Clin Endocrinol Metab (2002) 87:589-98. doi: 10.1210/jcem.87.2.8201

49. Hou Y, Zhang S, Wang L, Li J, Qu G, He J, et al. Estrogen Regulates Iron Homeostasis Through Governing Hepatic Hepcidin Expression via an Estrogen Response Element. Gene (2012) 511:398-403. doi: 10.1016/ j.gene.2012.09.060

50. Yang Q, Jian J, Katz S, Abramson SB, Huang X. 17beta-Estradiol Inhibits Iron Hormone Hepcidin Through an Estrogen Responsive Element Half-Site. Endocrinology (2012) 153:3170-8. doi: 10.1210/en.2011-2045

51. Bajbouj K, Shafarin J, Allam H, Madkour M, Awadallah S, El-Serafy A, et al. Elevated Levels of Estrogen Suppress Hepcidin Synthesis and Enhance Serum Iron Availability in Premenopausal Women. Exp Clin Endocrinol Diabetes (2018) 126:453-9. doi: 10.1055/s-0043-124077
52. Hennigar SR, Berryman CE, Harris MN, Karl JP, Lieberman HR, McClung JP, et al. Testosterone Administration During Energy Deficit Suppresses Hepcidin and Increases Iron Availability for Erythropoiesis. J Clin Endocrinol Metab (2020) 105(4):dgz316. doi: 10.1210/clinem/ $\operatorname{dgz} 316$

53. Guo W, Schmidt PJ, Fleming MD, Bhasin S. Hepcidin Is Not Essential for Mediating Testosterone's Effects on Erythropoiesis. Andrology (2020) 8:82-90. doi: 10.1111/andr.12622

54. Wang J, Liu G, Xu Z, Dai J, Song P, Shi J, et al. Hepcidin Levels in Hyperprolactinemic Women Monitored by Nanopore Thin Film Based Assay: Correlation With Pregnancy-Associated Hormone Prolactin. Nanomedicine (2015) 11:871-8. doi: 10.1016/j.nano.2015.01.008

55. Yovich JL, Regan SLP, Zaidi S, Keane KN. The Concept of Growth Hormone Deficiency Affecting Clinical Prognosis in IVF. Front Endocrinol (Lausanne) (2019) 10:650. doi: 10.3389/fendo.2019.00650

56. Saleem M, Martin H, Coates P. Prolactin Biology and Laboratory Measurement: An Update on Physiology and Current Analytical Issues. Clin Biochem Rev (2018) 39:3-16.

Conflict of Interest: The authors declare that the research was conducted in the absence of any commercial or financial relationships that could be construed as a potential conflict of interest.

Publisher's Note: All claims expressed in this article are solely those of the authors and do not necessarily represent those of their affiliated organizations, or those of the publisher, the editors and the reviewers. Any product that may be evaluated in this article, or claim that may be made by its manufacturer, is not guaranteed or endorsed by the publisher.

Copyright ๑ 2022 Krygier, Szczepanek-Parulska, Cieślewicz, Wrotkowska, ChanajKaczmarek and Ruchała. This is an open-access article distributed under the terms of the Creative Commons Attribution License (CC BY). The use, distribution or reproduction in other forums is permitted, provided the original author(s) and the copyright owner(s) are credited and that the original publication in this journal is cited, in accordance with accepted academic practice. No use, distribution or reproduction is permitted which does not comply with these terms. 